\title{
Desempenho agronômico de variedades e linhagens de soja em condições de baixa latitude em Teresina-PI ${ }^{1}$
}

\author{
Agronomic performance of varieties and strains of the soybean under low-latitude \\ conditions in Teresina, PI
}

\author{
Renato Santos Rocha ${ }^{2 *}$, José Algaci Lopes da Silva ${ }^{3}$, Josynaria Araújo Neves ${ }^{4}$, Tuneo Sediyama ${ }^{5}$ e Rita de Cássia \\ Teixeira $^{5}$
}

\begin{abstract}
Resumo - A pesquisa teve como objetivo avaliar o desempenho agronômico de variedades e linhagens de soja cultivadas sob baixa latitude, nas condições de Teresina-PI. Foram avaliadas as características fenológicas, produtivas e relacionadas ao desenvolvimento das plantas de soja de 32 genótipos, entre linhagens e variedades em fase de pré-lançamento, algumas já lançadas em Estados da Região Centro-Oeste do Brasil. O delineamento experimental empregado foi o de blocos casualizados, com quatro repetições. Nas condições estudadas, foram identificados 13 genótipos (nove variedades e quatro linhagens) com bons desempenhos agronômicos em baixas latitudes, com médias de produtividade de grãos acima de $2.900 \mathrm{~kg} \mathrm{ha}^{-1}\left(48,3\right.$ sacas de $\left.60 \mathrm{~kg} \mathrm{ha}^{-1}\right)$. Dos genótipos avaliados, tendo por base as testemunhas BRS Sambaíba e Msoy 9350, os que mais se destacaram dentre as características avaliadas e para uma colheita mecânica satisfatória, nas condições de baixa latitude, foram as variedades Conquista e Valiosa RR e, as linhagens BCR892 G132, BCR651 G75 e BCR6651 G68.
\end{abstract}

Palavras-chave - Glycine $\max ($ L.) Merrill . Soja. Plantas-desempenho.

\begin{abstract}
This study had as its objective to evaluate the agronomic performance of soybean varieties and strains grown under low-latitude conditions in Teresina, PI. Phenological traits, yield, and characteristics related to the development of soybean plants from 32 genotypes taken from pre-launch strains and varieties were evaluated, some already launched in states in the midwest region of Brazil. The experimental design used was of randomized blocks with four replications. Under the conditions studied, 13 genotypes (nine varieties and four strains) were identified as having good agronomic performance in low latitudes, with an average grain yield of over $2,900 \mathrm{~kg} \mathrm{ha}^{-1}$ (48.3 sacks of $\left.60 \mathrm{~kg} \mathrm{ha}^{-1}\right)$. Of those genotypes studied, based on certification of BRS Sambaíba and Msoy 9350, those that stood out most for the traits assessed and for satisfactory mechanical harvesting under low-latitude conditions, were the Conquista and Valiosa RR varieties and the strains BCR892 G132, BCR651 G75 and BCR6651 G68.
\end{abstract}

Key words - Glycine $\max$ (L.) Merrill. Soy. Plant-performance.

\footnotetext{
* Autor para correspondência

${ }^{1}$ Recebido para publicação em 16/06/2010; aprovado em 20/07/2011

Parte de Dissertação de Mestrado no CCA, Universidade Federal do Piauí

${ }^{2}$ Mestrado em Agronomia/Produção Vegetal/UFPI, Teresina-PI, Brasil, renato@agronomo.eng.br

${ }_{3}^{3}$ Departamento de Planejamento e Política Agrícola, CCA/UFPI, Teresina-PI, Brasil, algaci@ufpi.br

${ }^{4}$ Programa de Pós-Graduação em Agronomia/Produção Vegetal/UFPI, Teresina-PI, Brasil, josynaria@hotmail.com

${ }^{5}$ Centro de Ciências Agrárias/DFT, Universidade Federal de Viçosa, Viçosa-MG, Brasil, cebacuri@uol.com.br, cebacuri@uol.com.br
} 


\section{Introdução}

A soja (Glycine max (L.) Merrill) é uma espécie exótica para o Brasil e apresenta grande interesse socioeconômico, em função dos teores elevados de proteína $(40 \%)$ e óleo $(20 \%)$, da alta produtividade de grãos e da possibilidade de adaptação a ambientes diversos. Além disso, vem crescendo também como fonte de óleo para produção de biocombustível. Nesse sentido, o Brasil é considerado a grande promessa no fornecimento do esperado incremento da demanda mundial de soja, cujo crescimento médio, nos últimos 40 anos, tem sido da ordem de cinco milhões de toneladas por ano (GUIMARÃES et al., 2008).

Atualmente a cultura ocupa uma área mundial de 93,9 milhões de hectares, produzindo 236,08 milhões de toneladas. Os Estados Unidos são os maiores produtores mundiais com uma área plantada em 2006 de 30,19 milhões de hectares e produção de 86,8 milhões de toneladas. O Brasil é o segundo maior produtor mundial do grão com uma área de 20,69 milhões de hectares e produção de 58,4 milhões de toneladas (SEDIYAMA, 2009).

Grande parte da área mundial cultivada com soja está localizada em latitudes maiores que $30^{\circ}$, onde prevalecem condições de clima temperado. $\mathrm{O}$ Brasil representa uma exceção dentro desse contexto, pois cerca de metade da produção brasileira é colhida em latitudes menores que $20^{\circ}$. As regiões situadas em latitudes menores que $10^{\circ}$ representam atualmente as áreas de expansão da soja, especialmente nos Estados do Maranhão, Piauí, Tocantins e Pará (EMBRAPA, 2000).

A soja apresenta inúmeras pesquisas dirigidas para a obtenção de informações que possibilitem aumentos de produtividade. Considerando que o desenvolvimento da soja é influenciado por vários fatores ambientais, entre estes a temperatura, a precipitação pluvial, a umidade relativa do ar, a umidade do solo e, principalmente o fotoperíodo, a época de semeadura exerce influência decisiva sobre a quantidade e a qualidade da produção (MOTTA et al., 2000).

A recomendação de genótipos específicos para cada ambiente, a estratificação de uma área heterogênea em sub-regiões mais homogêneas e a identificação de genótipos com ampla adaptabilidade e estabilidade, tem sido as alternativas propostas para atenuar o efeito da interação genótipos x ambientes (PELÚZIO et al., 2005). Além disso, sua expansão sob condições de baixas latitudes foi alavancada com o lançamento de cultivares com características agronômicas de melhor adaptação às condições edafoclimáticas dos trópicos. Pesquisas que visam identificar cultivares mais adaptadas são de fundamental importância na otimização do sistema produtivo desta cultura, e certamente contribuirão, ainda mais, para o avanço da soja nas regiões de baixa latitude.

Dada a escassez de tais trabalhos na região e na expectativa de fornecer subsídios para uma escolha adequada de cultivares, objetivou-se verificar no presente trabalho o desempenho agronômico, em condições de baixa latitude, de variedades e linhagens de soja.

\section{Material e métodos}

O experimento foi instalado na área experimental do Departamento de Fitotecnia do Centro de Ciências Agrárias da Universidade Federal do Piauí, em Teresina - PI, e possui as seguintes coordenadas: latitude $05^{\circ} 02^{\prime} 39,95^{\prime}$ S, longitude $42^{\circ} 47^{\prime} 03,70^{\prime \prime} \mathrm{O}$ e altitude de $77 \mathrm{~m}$.

Na Tabela 1 encontra-se o resultado da análise físicoquímica do solo da área de instalação do experimento. A semeadura foi realizada no dia 18 de janeiro de 2008, pois nesse período encontra-se em meio à quadra chuvosa da região. O clima do município de Teresina é do tipo Aw' (tropical subúmido quente), conforme a classificação climática de Köppen (ANDRADE JÚNIOR et al., 2004), e possui duas estações definidas, seca (de junho a novembro) e chuvosa (de dezembro a maio). De acordo com Medeiros (2006), a região apresenta precipitação média anual de $1.377 \mathrm{~mm}$, sendo a maior concentração das chuvas nos meses de março e abril. Apresenta evapotranspiração potencial média anual de $2.973 \mathrm{~mm}$, umidade relativa do ar média anual de $69,9 \%$, insolação total anual de 2.625 h, temperatura média anual de $28{ }^{\circ} \mathrm{C}$, amplitude térmica de $11,5^{\circ} \mathrm{C}$, fotoperíodo médio anual de $12 \mathrm{~h}$ e $19 \mathrm{~min}$

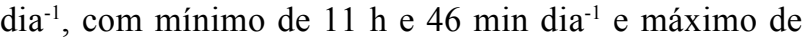
$12 \mathrm{~h}$ e $29 \mathrm{~min}^{\mathrm{dia}}{ }^{-1}$. Os dados de precipitação pluvial e temperatura média do ar durante o período experimental estão dispostos na Figura 1, de acordo com Bastos e Andrade Junior (2008).

Foram utilizados 32 genótipos como tratamentos. Variedades em fase de pré-lançamento e algumas já lançadas em Estados da Região Centro-Oeste: Conquista, Valiosa RR, Msoy 8008 RR, CD 219 RR, UFV 18 PM, P98 C81, BMS Topázio SM, BMS Ágata, BMS Ametista, BMS Ônix, BMS Turmalina, BMS Granada e DM 309. Linhagens utilizadas: BCR945 G110, BCR945 G114, BCR892 G132, BCR892 G140, BCR1070 G228, BCR1070 G229, BCR1070 G231, BCR1070 G244, BCR1070 G246, BCR1070 G251, BCR1067 G189, BCR1067 G210, BCR651 G68, BCR651 G75, BCR1057 G157, BCR1057 G162, BCR553 G306, todas obtidas junto ao programa de melhoramento de soja BMS - CEBACURI, com sede em Minas Gerais e Goiás. As variedades BRS Sambaíba e Msoy 9350 serviram como testemunhas regionais. 
Tabela 1 - Características químicas e físicas do solo $(0-20 \mathrm{~cm})$ da área experimental do Departamento de Fitotecnia do Centro de Ciências Agrárias, UFPI-PI

\begin{tabular}{|c|c|c|c|c|c|c|c|c|c|}
\hline \multicolumn{5}{|c|}{$\begin{array}{l}\text { Composição Granulométrica da Terra Fina } \\
\text { (dispersão com } \mathrm{NaOH} \mathrm{N}) \mathrm{g} \mathrm{kg}^{-1}\end{array}$} & Textura & $\begin{array}{l}\text { Densidade } \\
\text { aparente } \\
\mathrm{g} \mathrm{cm}^{-3}\end{array}$ & \multicolumn{3}{|c|}{ Umidade $\% \mathrm{Kg} \mathrm{kg}^{-1}$} \\
\hline \multirow{2}{*}{$\begin{array}{l}\text { Área grossa } \\
2-0,20 \mathrm{~mm}\end{array}$} & \multirow{2}{*}{$\begin{array}{c}\text { Área fina } 0,20- \\
0,05 \mathrm{~mm}\end{array}$} & \multirow{2}{*}{$\begin{array}{l}\text { Silte } 0,05- \\
0,002 \mathrm{~mm}\end{array}$} & \multirow{2}{*}{\multicolumn{2}{|c|}{$\begin{array}{c}\text { Argila } \\
<0,002\end{array}$}} & \multirow{3}{*}{$\begin{array}{l}\text { Areia } \\
\text { Franca }\end{array}$} & \multirow{3}{*}{1,53} & \multicolumn{2}{|c|}{$\mathrm{MPa}$} & \multirow{3}{*}{$\begin{array}{c}\text { Disponível } \\
(0,033-1,5) \\
3\end{array}$} \\
\hline & & & & & & & 0,033 & 1,5 & \\
\hline 320 & 510 & 130 & 40 & & & & 6 & 3 & \\
\hline \multicolumn{2}{|c|}{$\mathrm{pH}(1: 2,5)$} & \multicolumn{8}{|c|}{ Cátions Trocáveis $\left(\mathrm{cmol} \mathrm{Kg}^{-1}\right)$} \\
\hline Água & $\mathrm{KClN}$ & $\mathrm{Ca}^{2+}$ & $\mathrm{Mg}^{2+}$ & $\mathrm{K}^{+}$ & $\overline{\mathrm{Na}^{+}}$ & Valor S & $\mathrm{Al}^{3+}$ & $\mathrm{H}^{+}$ & Valor T \\
\hline 5,7 & 5,4 & 2,6 & - & 0,17 & 0,02 & 2,8 & - & 2,2 & 5,0 \\
\hline \multirow{2}{*}{$\begin{array}{l}\text { Valor V } \\
100 \mathrm{~S} \mathrm{~T}\end{array}$} & \multirow{2}{*}{$\begin{array}{l}\text { Sat. Com } \mathrm{Al}^{3+} \\
100 \mathrm{Al}^{3+} \mathrm{S}^{+} \mathrm{Al}^{3+}\end{array}$} & \multirow{2}{*}{\multicolumn{2}{|c|}{$\begin{array}{l}\text { P Assimilável } \\
\mathrm{mg} \mathrm{kg}^{-1}\end{array}$}} & & $\mathrm{C}$ & $\mathrm{N}$ & \multirow[b]{2}{*}{$\mathrm{CN}$} & \multirow{2}{*}{$\begin{array}{c}\text { Sat. } \\
\text { Com } \mathrm{Na}^{+} \\
100 \mathrm{Na}^{+} \mathrm{T}\end{array}$} & \multirow{2}{*}{$\begin{array}{c}\text { C.E. do } \\
\text { Extrato MS } \\
\mathrm{cm}^{-1}\end{array}$} \\
\hline & & & & & $\mathrm{g} \mathrm{Kg}$ & & & & \\
\hline 56 & - & 8,9 & & & 6,71 & 0,58 & 12 & - & 0,1 \\
\hline
\end{tabular}

Fonte: Laboratório de Analise de Solo do CCA/UFPI

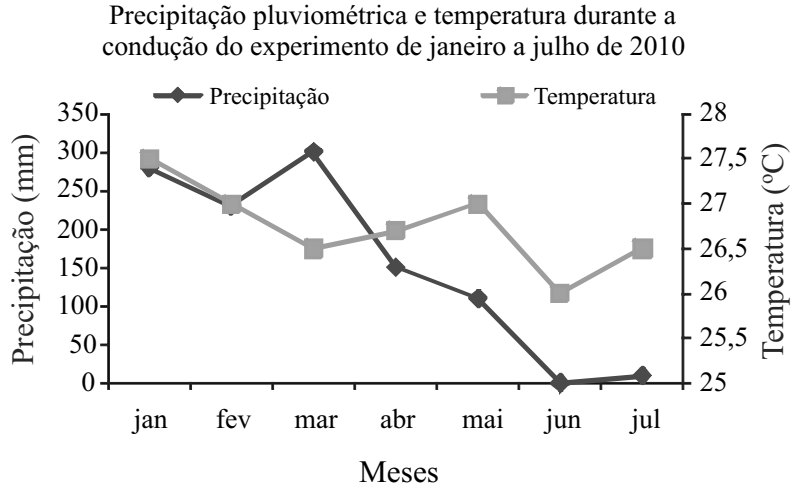

Figura 1 - Precipitação pluvial e temperaturas média mensal, observadas no decorrer da fase experimental, em Teresina-PI

$\mathrm{O}$ delineamento experimental empregado foi o de blocos casualizados, com quatro repetições. Cada parcela foi constituída de uma fileira de plantas com $5,0 \mathrm{~m}$ de comprimento e distância entre elas de $0,80 \mathrm{~m}$. Foi eliminado em cada linha $0,5 \mathrm{~m}$ de cada extremidade, utilizando-se uma área útil de $3,2 \mathrm{~m}^{2} \mathrm{em}$ cada parcela. No início e no final de cada bloco foi cultivada uma linha para reduzir os efeitos de bordadura.

A área foi preparada com gradagens e aplicação de herbicida, deixando-a apropriada para o plantio. As sementes foram inoculadas com bactérias pertencentes à espécie Bradyrhizobium japonicum e tratadas com molibdênio, inseticidas, fungicidas e bactericidas. A calagem foi feita antes da semeadura, com calcário Filler. Foi realizada uma adubação de fundação com $600 \mathrm{~kg} \mathrm{ha}^{-1}$ do formulado 0-30-20 (NPK) + FTE. No estádio $\mathrm{V}_{4}$ fezse uma aplicação foliar com molibdênio $\left(30 \mathrm{~g} \mathrm{ha}^{-1}\right)$, e no estádio $V_{10}$ uma outra com sulfato de manganês a $30 \%$ $\left(200 \mathrm{~g} \mathrm{ha}^{-1}\right)$. Fez-se o desbaste 15 dias após a emergência, deixando 15 plantas por metro linear $(187.500 \mathrm{mil}$ plantas $\mathrm{ha}^{-1}$ ). As plantas daninhas foram controladas por meio de capinas manuais. Aos 35 dias após a semeadura foi realizada uma adubação de cobertura com $60 \mathrm{~kg} \mathrm{ha}^{-1}$ de sulfato de amônio e $60 \mathrm{~kg} \mathrm{ha}^{-1}$ de cloreto de potássio.

Quando necessário, os tratos culturais exigidos pela cultura foram realizados, uniformemente em todas as parcelas experimentais. A colheita foi realizada manualmente durante o mês de maio, baseando-se no grau de umidade apresentado pelos grãos obtidos em cada parcela, que não ultrapassou $13 \%$ de umidade.

Avaliou-se as características relacionadas com a fenologia, ao desenvolvimento e ao desempenho produtivo dos genótipos, descritas a seguir:

a) Duração da juvenilidade: determinado em dias após a emergência até o início do florescimento. Estádio fenologicamente definido pela presença de $50 \%$ das plantas com uma flor aberta e simbolizado por $\mathrm{R}_{1}$ na escala fenológica de Fehr e Caviness (1977). Foram anotadas a data da emergência e a data de abertura das flores.

b) Duração do ciclo: determinado em dias após a emergência e o momento da maturação, simbolizado por $\mathrm{R}_{8}$ na escala fenológica de Fehr e Caviness (1977), o qual é definido pela presença de $50 \%$ das plantas da área útil com $95 \%$ das vagens maduras. Suas datas de ocorrência foram tabuladas e convertidas para número de dias. 
c) Altura média das plantas na maturidade: em centímetros (cm), medida a partir da superfície do solo até a inserção do rácemo do ápice da haste principal da planta, no estádio $\mathrm{R}_{8}$. Essa média foi determinada a partir da altura de 20 plantas amostradas aleatoriamente em cada parcela.

d) Altura média da primeira vagem: em centímetros $(\mathrm{cm})$, medida a partir da superfície do solo até a extremidade inferior da primeira vagem. Característica determinada pela média de 20 plantas amostradas aleatoriamente em cada parcela.

e) Índice de acamamento: foi avaliado utilizando-se a escala proposta por Bernard et al. (1965), na qual as parcelas foram classificadas através das notas: 1 - todas as plantas eretas; 2 - algumas plantas inclinadas ou ligeiramente acamadas; 3 - todas as plantas moderadamente inclinadas ou 25 a $50 \%$ das plantas acamadas; 4 - todas as plantas consideravelmente inclinadas ou 50 a $80 \%$ das plantas acamadas e; 5 - todas as plantas acamadas. Foi determinada a média a partir de três notas observadas por três avaliadores.

f) Peso médio de 100 grãos: peso médio, em gramas (g), das amostras separadas por um tabuleiro contador, em duas repetições de 100 sementes e pesadas em balança de precisão em cada parcela. g) Produtividade média de grãos: avaliada na maturidade final, após a colheita e beneficiamento através de debulha manual das vagens e pesagem dos grãos colhidos na área útil de cada parcela com umidade padronizada para $13 \%$. Os valores observados na parcela útil foram extrapolados para $\mathrm{kg} \mathrm{ha}^{-1}$.

Os dados foram submetidos à análise de variância e a comparação de médias pelo teste de Scott-Knott $(\mathrm{P}<0,05)$. Utilizou-se o software SAEG, versão 9.1, da Universidade Federal de Viçosa - UFV, Minas Gerais.

\section{Resultados e discussão}

Com base na análise de variância pode-se observar diferenças significativas entre os genótipos pelo teste $\mathrm{F}(\mathrm{P}<0,01)$, para todas as características avaliadas.

Na Tabela 2 são apresentados os valores de juvenilidade e o ciclo dos genótipos de soja estudados nas condições de baixa latitude. Houve pequena variação entre os genótipos testados com relação à duração do período de juvenilidade. Os genótipos Msoy 8008 RR, BMS Ônix e BCR $1070 \mathrm{G} 231$ foram os mais precoces no florescimento,

Tabela 2 - Valores médios de juvenilidade das plantas (JUV) e do número de dias para maturação (CICLO) dos genótipos de soja avaliados em baixa latitude, UFPI, Teresina - PI

\begin{tabular}{lccccc}
\hline \multicolumn{1}{c}{ Genótipos } & JUV (dias) & Ciclo (dias) & Genótipos & JUV (dias) & Ciclo (dias) \\
\hline BRS Sambaíba & $41,0 \mathrm{a}$ & $116,0 \mathrm{a}$ & BCR553 G306 & $32,5 \mathrm{~d}$ & $89,5 \mathrm{~b}$ \\
Msoy 9350 & $36,0 \mathrm{~b}$ & $110,7 \mathrm{a}$ & BCR1057 G157 & $32,5 \mathrm{~d}$ & $90,7 \mathrm{~b}$ \\
Conquista & $33,0 \mathrm{~d}$ & $102,7 \mathrm{a}$ & BCR1070 G246 & $33,0 \mathrm{~d}$ & $108,7 \mathrm{a}$ \\
Valiosa RR & $33,0 \mathrm{~d}$ & $96,0 \mathrm{~b}$ & BCR651 G68 & $33,0 \mathrm{~d}$ & $112,2 \mathrm{a}$ \\
BCR945 G114 & $31,5 \mathrm{e}$ & $105,7 \mathrm{a}$ & BCR1070 G228 & $32,5 \mathrm{~d}$ & $109,2 \mathrm{a}$ \\
BCR892 G140 & $32,0 \mathrm{e}$ & $103,7 \mathrm{a}$ & UFV 18 PM & $33,0 \mathrm{~d}$ & $105,2 \mathrm{a}$ \\
BCR1070 G244 & $31,0 \mathrm{e}$ & $107,5 \mathrm{a}$ & P98 C81 & $32,5 \mathrm{~d}$ & $105,2 \mathrm{a}$ \\
BCR1067 G210 & $33,0 \mathrm{~d}$ & $102,0 \mathrm{~b}$ & BMS Topázio SM & $33,0 \mathrm{~d}$ & $98,5 \mathrm{~b}$ \\
BCR945 G110 & $31,5 \mathrm{e}$ & $98,7 \mathrm{~b}$ & BMS Ágata & $34,0 \mathrm{c}$ & $107,0 \mathrm{a}$ \\
BCR892 G132 & $32,0 \mathrm{e}$ & $94,5 \mathrm{~b}$ & BMS Ametista & $34,0 \mathrm{c}$ & $113,7 \mathrm{a}$ \\
BCR651 G75 & $33,0 \mathrm{~d}$ & $111,7 \mathrm{a}$ & BMS Ônix & $31,0 \mathrm{f}$ & $114,7 \mathrm{a}$ \\
CD 219 RR & $34,7 \mathrm{c}$ & $104,5 \mathrm{a}$ & BMS Turmalina & $34,0 \mathrm{c}$ & $100,0 \mathrm{~b}$ \\
Msoy8008 RR & $30,7 \mathrm{f}$ & $108,5 \mathrm{a}$ & DM 309 & $33,0 \mathrm{~d}$ & $108,5 \mathrm{a}$ \\
BCR1067 G189 & $32,5 \mathrm{~d}$ & $96,5 \mathrm{~b}$ & BMS Granada & $31,5 \mathrm{e}$ & $114,2 \mathrm{a}$ \\
BCR1057 G162 & $33,0 \mathrm{~d}$ & $89,0 \mathrm{~b}$ & BCR1070 G229 & $33,0 \mathrm{~d}$ & $109,0 \mathrm{a}$ \\
BCR1070 G251 & $33,2 \mathrm{~d}$ & $101,2 \mathrm{~b}$ & BCR1070 G231 & $31,0 \mathrm{f}$ & $103,0 \mathrm{a}$ \\
\hline Média & - & & 33,0 & 104,3 \\
\hline C.V. (\%) & - & 1,81 & 7,19 \\
\hline
\end{tabular}

Médias seguidas pela mesma letra não diferem entre si pelo teste de Scott-Knott $(\mathrm{P} \leq 0,05)$ 
estatisticamente pelo teste de Scott-Knott a 5\%. Em contrapartida, a variedade testemunha BRS Sambaíba, com 41 dias da emergência até o florescimento, foi considerada a mais tardia em relação a essa característica.

Cruz et al. (2010), Shigihara e Hamawaki (2005) em experimentos com variedades com diferentes ciclos, obtiveram valores superiores em experimento nas latitudes $12^{\circ} 45^{\prime} 30^{\prime \prime} \mathrm{S}$ e $18^{\circ} 55^{\prime} 23^{\prime}$ ' S, variando de 40 a 56 e de 48 a 91 dias de juvenilidade, respectivamente, demonstrando a resposta fotoperiódica da cultura, onde os genótipos levaram poucos dias para florescerem na condição de baixa latitude, pois quanto mais se diminui a latitude, mais rápido os genótipos de soja florescem, por atingirem o fotoperíodo crítico em menor tempo. A temperatura é outro fator a se considerar, pois exerce influência em todas as fases fenológicas da soja. Nesse sentido, há uma interação entre fotoperíodo e temperatura, pois, temperaturas altas encurtam o período de florescimento e este efeito é mais acentuado em dias curtos.

As oscilações de temperaturas, acompanhadas de altos índices pluviométricos e flutuação de umidade relativa do ar, nas fases de maturação e pré-colheita da semente, geralmente ocasionam perdas na qualidade física, fisiológica e sanitária (COSTA et al., 2001).

De acordo com Sediyama et al. (1996) o aumento de temperaturas médias superiores a $24{ }^{\circ} \mathrm{C}$, em especial as noturnas, ocasiona rápido crescimento vegetativo, enquanto temperaturas inferiores a $24{ }^{\circ} \mathrm{C}$ normalmente retardam o florescimento em até três dias, para cada decréscimo de $0,5^{\circ} \mathrm{C}$. Desta maneira, as temperaturas em torno de $26{ }^{\circ} \mathrm{C}$, observadas em Teresina durante o período de desenvolvimento das plantas, contribuíram para o florescimento precoce dos genótipos testados.

Pelúzio et al. (2008) não observaram variações entre as cultivares nas duas épocas de semeadura quanto às características do número de dias para florescimento, número de dias para maturação dos grãos e altura de planta. Esses resultados estão em concordância com os obtidos por Barros et al. (2003) e Pelúzio et al. (2005).

Os genótipos BRS Sambaíba, BMS Ônix, BMS Granada, BMS Ametista, BCR651 G68, BCR651 G75, Msoy 9350, BCR1070 G228, BCR1070 G229, BCR1070 G246, Msoy 8008, DM 309, BCR1070 G244, BMS Ágata, BCR945 G114, UFV 18 PM, P 98 C 81, CD 219 RR, BCR892 G140, BCR1070 G231 e Conquista, apresentaram ciclos variando de 103 a 116 dias, se igualaram estatisticamente, caracterizando, a maioria destas, como de maturação precoce de acordo com Sediyama (2009). Os demais genótipos apresentaram ciclo mais precoce, variando de 89 a 102 dias para maturar os grãos (TAB. 2).
Os ciclos encontrados neste experimento diferem dos valores encontrados por Brugnera et al. (2006) em trabalho realizado na Bahia e no Piauí, em latitudes compreendidas entre $10^{\circ} 35^{\prime} 15^{\prime}, \mathrm{S}$ e $12^{\circ} 45^{\prime} 31^{\prime}, \mathrm{S}$, onde as cultivares BRS Sambaíba, Msoy 9350, BRS Valiosa RR e Conquista apresentaram ciclos de 130; 129; 114 e 114 dias, respectivamente. Cruz et al. (2010) encontraram também valores semelhantes em experimento na Bahia, em latitude $12^{\circ} 45^{\prime} 30^{\prime \prime} \mathrm{S}$. Portanto, mais longos que os ciclos encontrados neste trabalho, confirmando a influência do fotoperíodo e da temperatura no ciclo da cultura. Além da maturação destes genótipos terem sido aceleradas pelos dias mais curtos e pelas altas temperaturas, fazendo com que as plantas florescessem precocemente, encurtando o tempo necessário para maturação, ou seja, o ciclo. Característica que poderia ser considerada desejável, pois nessa região o período chuvoso é curto, sendo importante selecionar genótipos precoces, desde que sejam produtivos.

$\mathrm{Na}$ Tabela 3 encontram-se as notas dos índices de acamamento, os quais ficaram compreendidos entre 1,0 e 3,8. A maioria dos genótipos, num total de 21 , apresentou índice de acamamento das plantas igual ou inferior a 1,7 , com baixo número de plantas inclinadas ou muito pouco acamadas, os quais se diferenciaram estatisticamente dos demais. As maiores notas nesta variável foram obtidas pelos genótipos BCR1070 G229, BMS Ágata e BCR1070 G246, com 3,1; 3,2 e 3,8 respectivamente, os quais apresentaram entre 25 e $50 \%$ das plantas da área útil acamadas e se igualaram aos demais genótipos que obtiveram médias de acamamento igual ou superior a 2,0.

Segundo Shigihara e Hamawaki (2005), o acamamento afeta diretamente no desempenho das colhedoras, pois plantas acamadas significam perdas no rendimento de grãos, pela incapacidade do recolhimento dos grãos, além de poder ocasionar perdas pelo solo em contato direto com as vagens, pelo aparecimento de fungos e pragas. É influenciado não só pela ação dos ventos, mas ainda pelo tipo de solo e pelas condições de desenvolvimento da planta. Outro ponto a ser considerado refere-se à altura de planta. Normalmente, plantas mais altas poderão proporcionar maior índice de acamamento por apresentarem caules mais finos, ficando mais sujeitas ao tombamento pela ação dos ventos, o que não aconteceu no presente experimento (GUIMARÃES et al., 2008; ROCHA, 2001).

$\mathrm{Na}$ Tabela 4 estão apresentados os valores observados para altura de planta e altura da primeira vagem. Para altura de planta, os resultados foram significativos entre os tratamentos, apresentando variações de 43,5 a 73,4 cm. Pode-se observar que a cultivar testemunha BRS Sambaíba e a linhagem BCR1070 G229, que atingiram as médias de 73,4 e $66,6 \mathrm{~cm}$, respectivamente, foram as que apresentaram 
alturas superiores de plantas, não diferindo entre si pelo teste de Scott-Knott a nível de 5\%. Para essa característica outros nove genótipos se igualaram, estatisticamente, ficando em segundo lugar.

Tabela 3 - Valores médios do índice de acamamento (ACA) dos genótipos de soja cultivados em baixa latitude, UFPI, Teresina - PI

\begin{tabular}{|c|c|c|c|c|c|}
\hline Genótipo & ACA & Genótipo & ACA & Genótipo & ACA \\
\hline BRS Sambaíba & $1,1 \mathrm{~b}$ & CD 219 RR & $1,0 \mathrm{~b}$ & P98 C81 & $2,0 \mathrm{a}$ \\
\hline Msoy 9350 & $1,0 \mathrm{~b}$ & Msoy8008 RR & $1,0 \mathrm{~b}$ & BMS Topázio SM & $2,4 \mathrm{a}$ \\
\hline Conquista & $1,4 \mathrm{~b}$ & BCR1067 G189 & $1,2 \mathrm{~b}$ & BMS Ágata & $3,2 \mathrm{a}$ \\
\hline Valiosa RR & $1,2 \mathrm{~b}$ & BCR1057 G162 & $1,0 \mathrm{~b}$ & BMS Ametista & $1,3 \mathrm{~b}$ \\
\hline BCR945 G114 & $1,0 \mathrm{~b}$ & BCR1070 G251 & $2,1 \mathrm{a}$ & BMS Ônix & $1,0 \mathrm{~b}$ \\
\hline BCR892 G140 & $1,0 \mathrm{~b}$ & BCR553 G306 & $1,0 \mathrm{~b}$ & BMS Turmalina & $2,4 \mathrm{a}$ \\
\hline BCR1070 G244 & $2,6 \mathrm{a}$ & BCR1057 G157 & $1,0 \mathrm{~b}$ & DM 309 & $2,5 \mathrm{a}$ \\
\hline BCR1067 G210 & $1,0 \mathrm{~b}$ & BCR1070 G246 & $3,8 \mathrm{a}$ & BMS Granada & $2,1 \mathrm{a}$ \\
\hline BCR945 G110 & $1,0 \mathrm{~b}$ & BCR651 G68 & $1,5 \mathrm{~b}$ & BCR1070 G229 & $3,1 \mathrm{a}$ \\
\hline BCR892 G132 & $1,1 \mathrm{~b}$ & BCR1070 G228 & $1,7 \mathrm{~b}$ & BCR1070 G231 & $2,4 \mathrm{a}$ \\
\hline BCR651 G75 & $1,1 \mathrm{~b}$ & UFV 18 PM & $1,7 \mathrm{~b}$ & & \\
\hline Média & & & & & 1,6 \\
\hline C.V. $(\%)$ & - & & - & & 68,37 \\
\hline
\end{tabular}

Médias seguidas por letras distintas na coluna diferem entre si pelo teste de Skott-Knott $(\mathrm{P} \leq 0,05)$

Tabela 4 - Valores médios de altura média da planta (APL) e altura média da primeira vagem (APV) dos genótipos de soja cultivados em baixa latitude, UFPI, Teresina - PI

\begin{tabular}{lccccc}
\hline \multicolumn{1}{c}{ Genótipo } & APL $(\mathrm{cm})$ & APV $(\mathrm{cm})$ & Genótipo & APL $(\mathrm{cm})$ & APV $(\mathrm{cm})$ \\
\hline BRS Sambaíba & $73,4 \mathrm{a}$ & $17,9 \mathrm{a}$ & BCR553 G306 & $43,6 \mathrm{~d}$ & $9,2 \mathrm{e}$ \\
Msoy 9350 & $47,7 \mathrm{~d}$ & $11,6 \mathrm{~d}$ & BCR1057 G157 & $44,7 \mathrm{~d}$ & $10,0 \mathrm{~d}$ \\
Conquista & $59,7 \mathrm{~b}$ & $15,4 \mathrm{~b}$ & BCR1070 G246 & $58,0 \mathrm{~b}$ & $11,0 \mathrm{~d}$ \\
Valiosa RR & $60,7 \mathrm{~b}$ & $15,9 \mathrm{~b}$ & BCR651 G68 & $51,6 \mathrm{c}$ & $10,9 \mathrm{~d}$ \\
BCR945 G114 & $49,8 \mathrm{c}$ & $7,8 \mathrm{e}$ & BCR1070 G228 & $56,6 \mathrm{~b}$ & $9,3 \mathrm{e}$ \\
BCR892 G140 & $44,9 \mathrm{~d}$ & $8,0 \mathrm{e}$ & UFV 18 PM & $53,6 \mathrm{c}$ & $13,1 \mathrm{c}$ \\
BCR1070 G244 & $50,9 \mathrm{c}$ & $8,8 \mathrm{e}$ & P98 C81 & $56,1 \mathrm{~b}$ & $11,0 \mathrm{~d}$ \\
BCR1067 G210 & $45,5 \mathrm{~d}$ & $11,2 \mathrm{~d}$ & BMS Topázio SM & $54,2 \mathrm{c}$ & $14,4 \mathrm{c}$ \\
BCR945 G110 & $52,0 \mathrm{c}$ & $10,8 \mathrm{~d}$ & BMS Ágata & $58,1 \mathrm{~b}$ & $11,5 \mathrm{~d}$ \\
BCR892 G132 & $51,9 \mathrm{c}$ & $11,4 \mathrm{~d}$ & BMS Ametista & $51,2 \mathrm{c}$ & $9,0 \mathrm{e}$ \\
BCR651 G75 & $51,0 \mathrm{c}$ & $12,3 \mathrm{~d}$ & BMS Ônix & $45,2 \mathrm{~d}$ & $8,4 \mathrm{e}$ \\
CD 219 RR & $53,0 \mathrm{c}$ & $13,8 \mathrm{c}$ & BMS Turmalina & $61,4 \mathrm{~b}$ & $12,0 \mathrm{~d}$ \\
Msoy8008 RR & $46,0 \mathrm{~d}$ & $11,1 \mathrm{~d}$ & DM 309 & $61,1 \mathrm{~b}$ & $11,7 \mathrm{~d}$ \\
BCR1067 G189 & $45,8 \mathrm{~d}$ & $8,8 \mathrm{e}$ & BMS Granada & $51,0 \mathrm{c}$ & $10,4 \mathrm{~d}$ \\
BCR1057 G162 & $45,6 \mathrm{~d}$ & $10,3 \mathrm{~d}$ & BCR1070 G229 & $66,6 \mathrm{a}$ & $10,6 \mathrm{~d}$ \\
BCR1070 G251 & $59,1 \mathrm{~b}$ & $12,6 \mathrm{c}$ & BCR1070 G231 & $52,4 \mathrm{c}$ & $8,8 \mathrm{e}$ \\
\hline Médias & & & 53,21 & 7,49 & 11,22 \\
\hline C.V (\%) & & & & 12,32 \\
\hline
\end{tabular}

Médias seguidas por letras distintas na coluna diferem entre si pelo teste de Scott-Knott $(\mathrm{P} \leq 0,05)$ 
No Brasil, variedades comerciais normalmente apresentam altura média de 60 a $120 \mathrm{~cm}$ (BORÉM, 2000). Preconiza-se que as cultivares modernas de soja apresentem altura final de planta entre 60,0 a $110,0 \mathrm{~cm}$, não apenas para alta produtividade, mas também para elevado rendimento operacional da colhedora (SHIGIHARA; HAMAWAKI, 2005). Entretanto, Sediyama et al. (1996) consideraram que em solos planos e bem preparados pode-se efetuar uma boa colheita em plantas com 50,0 a 60,0 cm de altura, o que colocaria 21 dos 30 genótipos testados na condição de satisfatório para este aspecto.

Existe grande variabilidade entre os cultivares com relação à sensibilidade, à época de semeadura e às mudanças na região de cultivo. Por isso, são importantes os ensaios regionais de avaliação de cultivares de soja, realizados em diferentes épocas em uma mesma região (PEIXOTO et al., 2000). A altura de planta é característica fundamental na determinação da cultivar a ser introduzida em uma região, uma vez que está relacionada com o rendimento de grãos, controle de plantas daninhas e com as perdas durante a colheita mecanizada. As variações na altura das plantas podem ser influenciadas por época de semeadura, espaçamento entre e dentro das fileiras, suprimento de umidade, temperatura, fertilidade do solo, resposta fotoperiódica da cultivar e outras condições do ambiente.

Em relação à altura média da primeira vagem, a cultivar BRS Sambaíba apresentou um resultado superior, mantendo a média de $17,9 \mathrm{~cm}$, diferenciandose das demais, sendo seguida das cultivares Conquista e Valiosa RR, com 15,9 e 15,4 cm, respectivamente. Os genótipos BCR945 G114, BCR892 G140, BCR553 G306, BCR1070 G228, BCR1070 G244, BCR1067 G189, BMS Ametista, BMS Ônix e BCR1070 G231 apresentaram as menores médias de altura da primeira vagem, variando de 7,8 a 9,3 cm (TAB. 4), respectivamente, o que, dependendo do relevo e preparo do solo, provocaria perdas consideráveis na colheita.

Para um elevado rendimento operacional da colhedora, associado à minimização de perdas de colheita, Valadão Junior et al. (2008) recomendam que, em terrenos planos, as cultivares de soja devem apresentar altura da primeira vagem igual ou superior a $10,0 \mathrm{~cm}$. Em termos práticos, nove genótipos (BCR945 G114, BCR892 G140, BCR1070 G244, BCR1067 G189, BCR553 G306, BCR1070 G228, BMS Ametista, BMS Ônix e BCR1070 G231) não atenderam a esse critério (TAB. 4).

A altura das plantas e a altura de inserção da primeira vagem são características que sofrem variações em função da densidade de plantas. Assim, as maiores populações estimularam o crescimento das plantas e a elevação da altura de inserção da primeira vagem (PELUZIO et al., 2002). Entretanto, para a maioria das condições das lavouras de soja, a altura mais satisfatória está em torno de 15,0 cm, embora colhedoras mais modernas possam efetuar boa colheita com plantas apresentando primeiro legume a $10,0 \mathrm{~cm}$.

Os valores observados para peso médio de 100 grãos e produtividade de grãos são apresentados na Tabela 5. Houve variação de 15,29 a 20,78 g nos valores encontrados no peso de 100 grãos, os quais foram superiores nos genótipos Conquista, BMS Ônix, BMS Granada, BCR1070 G251 e BCR1070 G229, variando de 19,00 a 20,78 g (TAB. 5).

A média obtida para peso médio de 100 grãos foi de 17,16 g (TAB. 5), superior a encontrada por Brugnera et al. (2006), que obteve média de 15,71 g. Conforme resultados obtidos por Xavier et al. (2008), para a característica peso médio de 100 grão a cultivar Candeia apresentou um comportamento fenotípico inferior, o qual resultou em aumento na produtividade de grãos.

Ainda na Tabela 5, observou-se para a característica produtividade de grãos, variação de 1.485 a $3.585 \mathrm{~kg} \mathrm{ha}^{-1}$ (24,8 a 59,8 sacas de $\left.60 \mathrm{~kg} \mathrm{ha}^{-1}\right)$. Treze genótipos (BCR651 G68, BRS Sambaíba, BCR651 G75, BCR1070 G251, DM 309, BMS Ametista, Msoy 9350, P98 C81, UFV 18 PM, Valiosa RR, BCR892 G132, Conquista e BMS Granada) apresentaram as maiores médias de produtividade, não diferindo, estatisticamente, entre si, com amplitude de produtividade de $2.900 \mathrm{~kg} \mathrm{ha}^{-1}$ (48,3 sacas de $60 \mathrm{~kg} \mathrm{ha}^{-1}$ ) a $3.585 \mathrm{~kg} \mathrm{ha}^{-1}\left(59,7\right.$ sacas de $\left.60 \mathrm{~kg} \mathrm{ha}^{-1}\right)$. Deve-se destacar que, destes 13 genótipos, apenas a variedade BMS Granada ficou abaixo de $3.000 \mathrm{~kg} \mathrm{ha}^{-1}$. O pior valor de rendimento foi apresentado pela variedade Msoy $8008 \mathrm{RR}$, com 1.486,0 $\mathrm{kg} \mathrm{ha}^{-1}$, igualando-se às demais não citadas (TAB. 5).

As médias de produção estão relativamente baixas em relação aos resultados encontrados nos trabalhos de Brugnera (2006) e Cruz (2010), e se igualam aos resultados encontrados por Guimarães et al. (2008). Dias et al. (2009) trabalhando com as cultivares BRS TRACAJÁ, MA BR 97 1665, BRS JUÇARA, BRS MA 165 SERIDÓ, BRS 219 BOA VISTA, BRS CANDEIA e BRS SAMBAÍBA nos municípios de Pentecoste e de Quixadá, concluíram que os genótipos BRS TRACAJÁ, BRS SAMBAÍBA e MA BR 971665 apresentaram produção de grãos acima da média geral, ampla adaptabilidade, demonstrando potencial para serem cultivadas no Estado do Ceará.

A interação genótipo $\mathrm{x}$ ambiente no rendimento de grãos pode tornar onerosa e lenta a seleção de genótipos com características promissoras (CARVALHO et al., 2002). No entanto, o aumento de produção e da área plantada é 
Tabela 5 - Valores médios do peso médio de 100 grãos (PG) e produtividade de grãos (PROD) dos genótipos de soja cultivados em baixa latitude, UFPI, Teresina - PI

\begin{tabular}{lccccc}
\hline \multicolumn{1}{c}{ Genótipo } & PG $(\mathrm{g})$ & PROD $\left(\mathrm{kg} \mathrm{ha}^{-1}\right)$ & Genótipo & PCG $(\mathrm{g})$ & PROD $(\mathrm{kg} \mathrm{ha})^{-1}$ \\
\hline BRS Sambaíba & $15,37 \mathrm{~d}$ & $3.536,1 \mathrm{a}$ & BCR553 G306 & $15,79 \mathrm{~d}$ & $2.404,5 \mathrm{~b}$ \\
Msoy 9350 & $15,77 \mathrm{~d}$ & $3.305,0 \mathrm{a}$ & BCR1057 G157 & $16,07 \mathrm{~d}$ & $2.312,6 \mathrm{~b}$ \\
Conquista & $19,99 \mathrm{a}$ & $3.048,8 \mathrm{a}$ & BCR1070 G246 & $18,10 \mathrm{~b}$ & $1.834,7 \mathrm{~b}$ \\
Valiosa RR & $18,62 \mathrm{~b}$ & $3.107,6 \mathrm{a}$ & BCR651 G68 & $18,09 \mathrm{~b}$ & $3.585,8 \mathrm{a}$ \\
BCR945 G114 & $15,21 \mathrm{~d}$ & $2.295,1 \mathrm{~b}$ & BCR1070 G228 & $17,92 \mathrm{~b}$ & $2.391,6 \mathrm{~b}$ \\
BCR892 G140 & $14,92 \mathrm{~d}$ & $2.485,4 \mathrm{~b}$ & UFV 18 PM & $18,56 \mathrm{~b}$ & $3.115,8 \mathrm{a}$ \\
BCR1070 G244 & $17,72 \mathrm{~b}$ & $2.168,3 \mathrm{~b}$ & P98 C81 & $17,20 \mathrm{c}$ & $3.278,4 \mathrm{a}$ \\
BCR1067 G210 & $15,53 \mathrm{~d}$ & $2.312,8 \mathrm{~b}$ & BMS Topázio SM & $16,59 \mathrm{c}$ & $2.574,5 \mathrm{~b}$ \\
BCR945 G110 & $16,21 \mathrm{c}$ & $2.369,2 \mathrm{~b}$ & BMS Ágata & $15,29 \mathrm{~d}$ & $2.623,0 \mathrm{~b}$ \\
BCR892 G132 & $16,71 \mathrm{c}$ & $3.073,2 \mathrm{a}$ & BMS Ametista & $16,81 \mathrm{c}$ & $3.325,3 \mathrm{a}$ \\
BCR651 G75 & $16,98 \mathrm{c}$ & $3.502,4 \mathrm{a}$ & BMS Ônix & $19,05 \mathrm{a}$ & $1.926,3 \mathrm{~b}$ \\
CD 219 RR & $16,32 \mathrm{c}$ & $2.378,0 \mathrm{~b}$ & BMS Turmalina & $16,04 \mathrm{~d}$ & $2.599,0 \mathrm{~b}$ \\
Msoy8008 RR & $17,61 \mathrm{~b}$ & $1.486,0 \mathrm{~b}$ & DM 309 & $17,57 \mathrm{~b}$ & $3.383,2 \mathrm{a}$ \\
BCR1067 G189 & $16,29 \mathrm{c}$ & $2.123,9 \mathrm{~b}$ & BMS Granada & $19,56 \mathrm{a}$ & $2.905,8 \mathrm{a}$ \\
BCR1057 G162 & $15,41 \mathrm{~d}$ & $2.178,3 \mathrm{~b}$ & BCR1070 G229 & $20,78 \mathrm{a}$ & $2.353,9 \mathrm{~b}$ \\
BCR1070 G251 & $19,91 \mathrm{a}$ & $3.406,6 \mathrm{a}$ & BCR1070 G231 & $17,28 \mathrm{c}$ & $2.057,5 \mathrm{~b}$ \\
\hline Média & & & 17,16 & 4,88 & $2.670,3$ \\
\hline C.V. (\%) & & & & 18,61 \\
\hline
\end{tabular}

Médias seguidas por letras distintas na coluna diferem entre si pelo teste de Skott-Knott $(\mathrm{P} \leq 0,05)$

obtido em função da tecnologia utilizada, especialmente, o uso de sementes de qualidade que é indispensável para o sucesso de qualquer lavoura produtora de grãos e sementes (LOPES et al., 2002).

Sabe-se que os fatores climáticos que condicionam o ambiente são determinantes no grau de adaptação dos indivíduos e o potencial de rendimento de grãos pode ser influenciado por estes fatores, principalmente a umidade, temperatura e fotoperíodo que variam com as diferentes épocas do ano. Assim, os altos rendimentos podem ser obtidos quando as condições relatadas anteriormente estão em todos os estádios de desenvolvimento (GUIMARÃES, et al. 2008). Dentro desse contexto, não se observou fatos relevantes que pudessem ter influenciado negativamente a produção nesse experimento, principalmente no que diz respeito ao aspecto nutricional ou de suprimento de água para as plantas.

\section{Conclusão}

Dos genótipos avaliados, tendo por base as testemunhas BRS Sambaíba e Msoy 9350, os que se destacam dentre as características avaliadas, nas condições de baixa latitude, são as variedades Conquista e Valiosa RR e, as linhagens BCR892 G132, BCR651 G75 e BCR6651 G68, todas apresentando condições satisfatórias para a colheita mecânica.

\section{Referências}

ANDRADE JÚNIOR et al. Classificação climática do Estado do Piauí. Teresina: Embrapa Meio-Norte. 2004. 86 p. (Documentos, 86).

BARROS, H. B. et al. Efeito das épocas de semeadura no comportamento de cultivares de soja, no sul do estado do Tocantins. Revista Ceres, v. 50, n. 291, p. 565-572, 2003.

BASTOS, E. A.; ANDRADE JÚNIOR, A. S. Boletim agrometeorológico do ano de 2007 para o município de Teresina, PI. Teresina-PI: Embrapa Meio-Norte, 2008.

BERNARD, R. L.; CHAMBERLAIN, D. W.; LAWRENCE, R. E. Results of the cooperative uniform soybean tests. Washington: USDA, 1965. $134 \mathrm{p}$.

BORÉM, A. Escape gênico: os riscos do escape gênico da soja no Brasil. Biotecnologia Ciência e Desenvolvimento, v. 10, p. 101-107, 2000. 
BRUGNERA, A. et al. Competição de cultivares de soja avaliados em diferentes regiões do cerrado. Barreiras: Fundação Bahia, 2006. 1-7 p (Comunicado técnico, Safra 2005/2006).

CARVALHO, C. G. P. et al. Interação genótipo x ambiente no desempenho produtivo da soja no Paraná. Pesquisa Agropecuária Brasileira, v. 37, n. 07, p. 989-1000, 2002.

COSTA, N. P. et al. Efeito da colheita mecânica da soja nas características físicas, fisiológicas e químicas das sementes em três estados brasileiros. Revista Brasileira de Sementes, v. 23, n. 01, p. 140-145, 2001.

CRUZ, T. V. da et al. Crescimento e produtividade de soja em diferentes épocas de semeadura no oeste da Bahia. Scientia Agraria, v. 11, n. 01, p. 033-042, 2010.

DIAS, F. T. C. et al. Adaptabilidade e estabilidade fenotípica para o caráter rendimento de grãos em cultivares de soja para o Estado do Ceará. Revista Ciência Agronômica, v. 40, n. 01, p. 129-134, 2009.

EMPRESA BRASILEIRA DE PESQUISA AGROPECUARIA (EMBRAPA). Centro Nacional de Pesquisa de Soja. A cultura da soja no Brasil. Londrina: Embrapa Soja, 2000. 179 p.

FEHR, W. R.; CAVINESS, C. E. Stages of soybean development. Ames: Iowa State University of Science and Technology, 1977. $11 \mathrm{p}$.

GUIMARÃES, F. S. et al. Cultivares de soja [Glycine max (L.) Merrill] para cultivo de verão na região de Lavras-MG. Ciência e Agrotecnologia, v. 32, n. 04, p. 1099-1106, 2008.

LOPES, J. C. et al. Avaliação da qualidade fisiológica de sementes de soja produzidas em Alegre-ES. Revista Brasileira de Sementes, v. 24, n. 01, p. 51-58, 2002.

MEDEIROS, R. M. Climatologia do município de Teresina. Teresina: Secretaria do Meio Ambiente e Recursos Naturais do Estado do Piauí, 2006. 28 p.
MOTTA, I. S. et al. Características agronômicas e componentes da produção de sementes de soja em diferentes épocas de semeadura. Revista Brasileira de Sementes, v. 22, n. 02 , p. 153-162, 2000.

PEIXOTO, C. P. et al. Época de semeadura e densidade de plantas de soja: I. Componentes da produção e rendimento de grãos. Scientia Agrícola, v. 57, n. 01, p. 89-96, 2000.

PELÚZIO, J. M. et al. Comportamento de cultivares de soja no Sul do Estado do Tocantins. Bioscience Journal, v. 01, n. 03, p. 113-117, 2005.

PELÚZIO, J. M. et al. Comportamento de cultivares de soja sob condições de várzea irrigada no sul do estado do Tocantins, entressafra 2005. Bioscience Journal, v. 24, n. 01, p. 75-80, 2008.

ROCHA, R. N. C. et al. Comportamento de cultivares de soja em diferentes populações de plantas, em Gurupi, Tocantins. Revista Ceres, v. 48, n. 279, p. 529-537, 2001.

SEDIYAMA, T. (Org.). Tecnologias de produção e usos da soja. Londrina, Paraná: Mecenas, 2009. 314 p.

SEDIYAMA, T. et al. Cultura da Soja - I Parte.. Viçosa: UFV, 1996. $96 \mathrm{p}$.

SHIGIHARA, D; HAMAWAKI, O. T. Seleção de Genótipos para Juvenilidade em Progênies de soja (Glycine max (L.) Merrill). Bioscience Journal. Universidade Federal de Uberlândia (UFU), Uberlândia-MG, p. 01-26, 2005.

SISTEMA PARA ANÁLISES ESTATÍSTICAS. Versão 9.1: Viçosa: Fundação Arthur Bernardes - UFV - 2007.

VALADÃO JÚNIOR, D. et al. Adubação fosfatada na cultura da soja em Rondônia. Scientia Agraria, v. 09, n. 03, p. 369$375,2008$.

XAVIER, T. F. et al. Comportamento fenotípico em casa de vegetação de cultivares de soja na região norte do Piauí. Caatinga, v. 21, n. 04, p. 05-08, 2008. 